\title{
Design and Analysis of Microinverter Based Solar Grid Tied Photovoltaic System
}

\author{
Er. Sandesh Kunwar, Dr. Prof. Laxman Poudel
}

\begin{abstract}
This study intends to design and perform financial analysis of the solar photovoltaic (PV) microinverter for grid connected system. A micro-inverter is the portable inverter used in photovoltaics, that inverts direct current (DC) produced by a solar module to alternating current (AC). Microinverter with low frequency transformer configuration design is considered for the research. For grid connected system, microinverter needs to synchronize voltage and frequency while injecting active power to the grid, so Phase Locked Loop (PLL) has been used in microinverter control algorithm. The coordinated design of LCL filter circuit and current control algorithm is used to limit the harmonic of the system within the 5 percent and regulated the output voltage and frequency within the grid limit. About 12 PV module with capacity of $2.8 \mathrm{~kW}$ microinverter system and equivalent string inverter PV system is simulated in MATLAB. In the computer-based simulation, when 2 or more PV modules are shaded in the string configuration, there is drastically decrease of DC voltage causing system to collapse unlike microinverter system where the performance of shaded microinverter doesn't impact the output voltage of others
\end{abstract}

Index Terms- Grid connected Inverter, LCL, Microinverter, Current control algorithm

\section{INTRODUCTION}

The global population growth is increasing in every year but present supply of conventional energy is limited to us. There is need to increase the energy sources and look for the environmentally friendly, reliable and cheap resources required to support them.

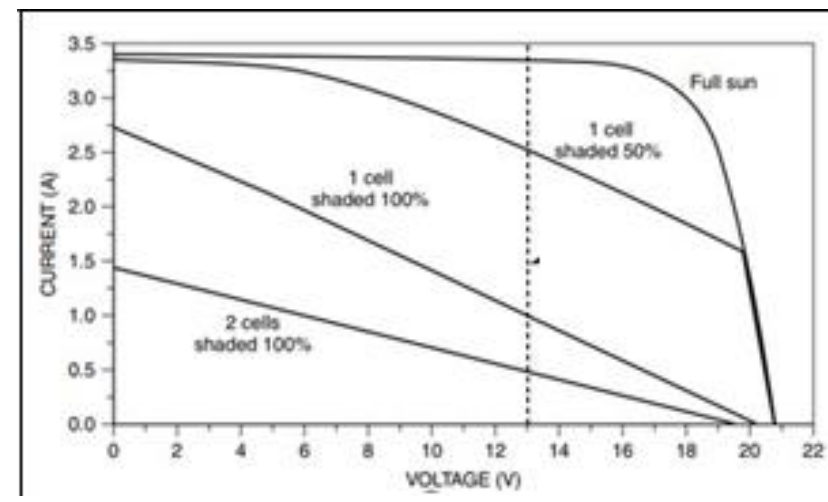

Figure 1: Shading effect on Solar cell

Lot of research have going to improve the reliability of renewable resources and make them economically and technically feasible to everyone. One of the easily available and free energy sources is solar energy. Solar energy is one of

Sandesh Kunwar, Electrical Engineer, MSC in Renewable Engineering, Pulchowk Campus, IOE, TU

Dr Laxman Poudel, Professor, Mechanical Department, Pulchowk Campus,IOE, TU, Nepal the most important present and future renewable resources, so grid-connected solar farms are going to be popular in the upcoming years. Distributed generation has been encouraged by the government and the utility to support the increasing demand in the distribution networks.

While these Distributed Generations (DGs) are supporting the grid, they are causing the problems regarding stability. So,

problems such as voltage regulations and instability can be caused by suddenly increased demand, switching of load, faults etc. It is found that with bypass diodes, the efficiency of a PV system can be improved especially when the number of PV cells within a bypass diode is small. A microgrid is a small-scale power grid that can operate independently or collaboratively with other small power grids or coordinately with power grid. With the incoming high penetration of distributed generation (DG), both electric utilities and end users of electric power are becoming increasingly concerned about the quality of electric network. The IEEE standard 1547 defines regulation and limit of the ancillary services in distributed power generation systems (DPGSs) such as: load regulation, energy losses, spinning and non-spinning reserves, voltage regulation, and reactive-power supply.

Shading can have a huge impact on the performance of solar photovoltaic panels. Even if a small section of the photovoltaic panel is shaded, output power of photovoltaic panel will reduce significantly. As already stated, solar photovoltaic panels consist of a number of photovoltaic cells which are wired together into a series to get the required voltage. As the cells are wired in series and parallel to get required voltage and current, interference of parallel branch will be affected due to shaded module, even if single cell is shaded. Substantial power loss can occur due to non-uniform illumination of a series string and power generated by highly illuminated cells is wasted as a heat in the poorly illuminated cells.

There are various method by which effect of shading can be decreased. Some of the common method are Blocking Diode and Bypass diodes. But recently, with the improvement of technology, microinverter has been considered better alternative than above method, which provides modularity and efficiency. So, Microinverter has been considered one of the important technique to mitigate those effect and control the energy in modular level. In grid tied system, control of harmonics and synchronizing with the grid is very important to maintain the relaiblity. Microinverter configuration become the more cost effective system when the replacement costs associated with the expected string inverter failure is considered.

Filtering of the power coming from inverter i.e. Voltage Source Converte(VSC) is a necessary task to control injected harmonics. Normally, VSCs are connected to the grid using L (Inductor) and LC (Inductor Capacitor) filter, but at low 
frequencies the $\mathrm{L}$ and LC filters becomes bulky and expensive. So, to reduce the cost and the size parameters, the LCL filter has been considered.

\section{MethodOlOGY}

This section deals with the design of microinverter and performance analysis of the designed microinverter with the scheme for the grid Connected Solar PV configuration model. As line frequency transformers are used in case of a single-stage centralized PV inverter to increase the inverter voltage to grid [1].

Solar PV module considered for Microinverter is Solar cell: Trina Solar TSM 250P AP05 which is 250W solar Panel. The detail procedure for microinverter modelling are as:

- Selection for Solar PV module and review of its V-I profile for different irradiance

- Selection of Maximum power Point Tracking (MPPT) algorithm for tracking maximum power point

- Transformation of sinusoidal waveform to constant DC waveform for controlling output power or voltage and current as required item

- Determination of Transfer function of LCL filter of themicroinverter

- Calculation of LCL i.e. inductor and capacitor value using the algorithm as provided in Appendix as per the harmonic elimination,

- Determination of control algorithm for the microinverter

After the microinverter modelling, then string inverter PV configuration is compared with microinverter model to analysis for efficiency and performance.

\section{A. Maximum Power Point Tracking (MPPT)}

MPPT is used to track the maximum power as per PV module irradiance level. Some of the major MPPT algorithm that are widely used are: Perturb and observe, Incremental conductance and Temperature Method.

In this research, Perturbation and observation algorithm have been used for MPPT control in order to ensure maximum power due to its simplicity. The coordination among individual proposed control methods: MPPT control at the PV side, and V-f / P-Q control algorithm at the inverter side is critical and interrelated [2]. These two control algorithms at different stages are jointly linked through a power balance objective at the DC and AC side of the inverter so that the DC side voltage is indirectly controlled at the desired value.

\section{B. Phase Locked Loop (PLL):}

PLL is important to track the grid frequency and phase angle. This grid phase angle is used to synchronized the inverter and grid voltage. The compensator in MATLAB environment has been developed for PLL tracking. The compensator has been considered from the page 214 of chapter 8 , example 8.1 of [3], where detail procedure for the compensator $\mathrm{H}(\mathrm{s})$ is done,

Transfer function of the compensator used for PLL is $H(s)=\frac{a s^{4}+b s^{3}+c s^{2}+d s^{1}+e}{f s^{4}+g s^{4}+b h+i s^{2}+j s^{1}}$
Where $\mathrm{a}=685.42, \mathrm{~b}=113779.72, \mathrm{c}=394394095.1$, $\mathrm{d}=64685591295.52, \mathrm{e}=2684452038764.08, \mathrm{f}=1, \mathrm{~g}=2472$. $\mathrm{h}=2254552, \mathrm{i}=898394016$ and $\mathrm{j}=132079911184$.

The designed PLL block consist of transfer function of equation 3.1, saturation block and VCO as main block with the feedback del or wt.

del is the phase angle of the grid voltage. The del_1 and del_2 are the phase angle derived from the MATLAB default model and designed from transfer function $\mathrm{H}(\mathrm{s})$ i.e. equation 3 . Then the program was simulated for about three second for the signal of $60 \mathrm{hz}$ frequency system. Both of the system of PLL provides identical output with slight error at the end of each cycle which is minor and can be neglected.

(a)

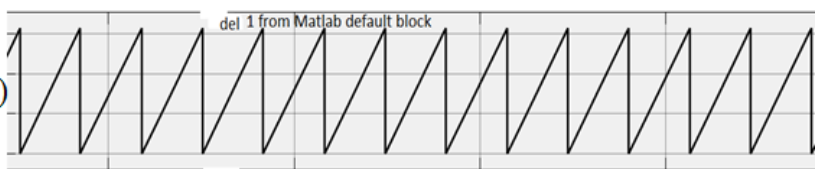

(b)

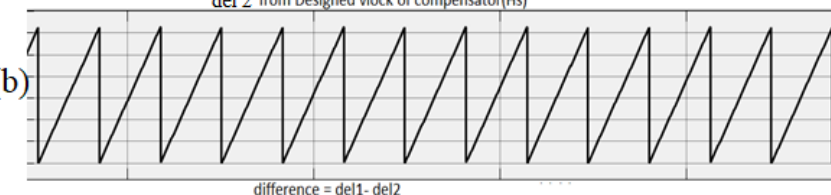

(c)

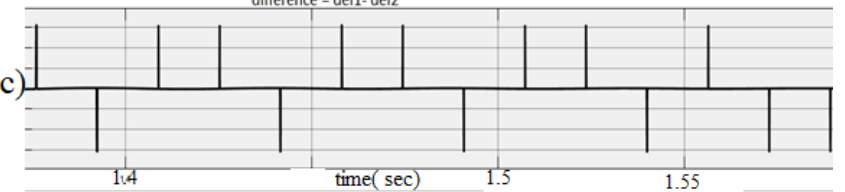

Figure 2: (a) MATLAB default PLL, (b) designed PLL and (c) its error

Then the program was simulated for about three second for the signal of $60 \mathrm{hz}$ frequency system. Both of the system of PLL provides identical output with slight error at the end of each cycle which is minor and can be neglected. Since the compensator designed consume more memory and simulation cycle, so MATLAB default PLL for this research has been considered.

\section{Single phase to (direct-quadrature) dq transformation}

$\mathrm{dq}$ transformation is widely used for three phase converter analysis and control design. It is a form of transformation between stationary and rotating frames. State variables of a three-phase converter are transformed into alpha beta frame which is a two-phase stationary coordinate. Once state variables mapped into alpha beta frame, a transformation from alpha beta to dq rotating frame is applied by providing the phasor of the source.

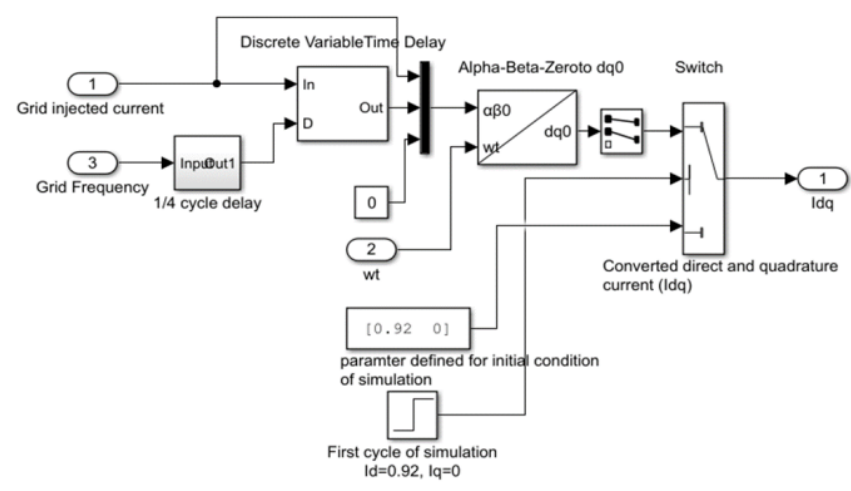

Figure 3: dq transformation for current 
Since there is requirement of alternating signals having phase difference, but in case of single phase (i.e. voltage or current) has only one phase. So alternative transformation is done for single phase by applying 90-degree phase shift [4] where original signal as alpha- axis value and shifted signal as beta axis value which is then transformed using the alpha beta to dq transformation principle.

For Voltage, transformation is done using block Fundamental PLL of the MATLAB which provide phase and magnitude of the signal in refence to Frequency and phase (input from the PLL). As wt and frequency is generated from grid voltage, so no phase shift required. The signal is converted to $\mathrm{dq}$ axis using complex function.

\section{LCL Filter circuit:}

LCL filter Parameter calculation is very important as it helps to reduce harmonics and improve the current profile injected in the grid. As per [5] and [6], the minimum inverter side inductor is given by

$L_{\min }=V d c /\left(3 * f_{s w} * d e I_{-} I_{\max }\right)$

Where Vdc is the DC input voltage to the inverter, $\mathrm{f}_{\mathrm{sw}}$ is the switching frequency of PWM, del_ $I_{\max }$ is the maximum ripple voltage.

The grid side inductor and and capacitor for the filter is calculated as:

$L_{2}=r * L_{1}$

$$
C_{f}=0.01 * C_{b}
$$

Where $r$ is the ratio between the inductance at the inverter side and the one at the grid side and $\mathrm{C}_{\mathrm{b}}$ is the base capacitance.

After the above basic calculation of $\mathrm{Li}, \mathrm{C}_{\mathrm{f}}$ and $\mathrm{L} 2$, then the parameter should satisfy below condition of resonance frequency for stable operation. The grid side whether inductance is influenced by the grid reactance, since it depends on the nature of the grid whether it is strong or weak. The maximum of inductance of $1 \mathrm{mH}$ is considered for this analysis which is added to grid side inductor for to check the below condition. The minimum and maximum resonance frequency limit as per the grid reactance is given by:

$f_{\text {resmin }}=\frac{1}{2 \cdot P I}\left(\frac{L_{2 \max }+L_{i}}{L_{2 \max } L i \cdot C f \max }\right)^{1 / 2}$

$f_{\text {resmax }}=\frac{1}{2 * P I}\left(\frac{L_{2 \min }+L_{i}}{L_{2 \min } L i \text { Cf } \min }\right)^{1 / 2}$

Then the condition for resonance frequency $f_{\text {res }}$ to satisfy is as:

$f_{\text {resmin }} \leq f_{\text {res }} \leq f_{\text {resmax }}$

Also, we should consider the switching frequency of the PWM which may resonant with the LCL parameter so it also should satisfy the following condition:

$$
10 * f_{g} \leq f_{\text {resmin }} \leq f_{\text {res }} \leq f_{\text {resmax }} \leq f_{\text {sw }} / 2
$$

Since main concern of this research is grid current and inverter voltage so we consider the transfer function (T) considering grid voltage zero. In order to simply the calculation we shall neglect $\mathrm{Ri}$ and $\mathrm{Rg}$. The transfer function of the above at grid voltage $=0$ is given as:

$$
T=i_{g} / V_{i}=\frac{a * s+1}{b s^{3}+C s^{2}+d S}
$$

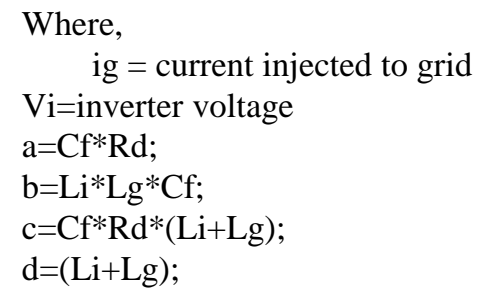

As per [5] and [6], above are the some of the major criteria for smooth performance to eliminate resonance effect due to grid and PI controller in order to generate the smooth output with less harmonics. The value of $\mathrm{L}$ and $\mathrm{C}$ can't be obtained in one calculation, there is need of recursive i.e. repetitive calculation till it satisfy all the above values.

\section{E. Current Control algorithm}

There are two main controller mode i.e. voltage control and current mode for inverter. The voltage-mode control is simple and has a low number of control loops. However, the main shortcoming of the voltage-mode control is that there is no control loop closed on the VSC line current. Consequently, the VSC is not protected against overcurrent, and the current may undergo large excursions if the power commands are rapidly changed or faults take place in the AC system. The

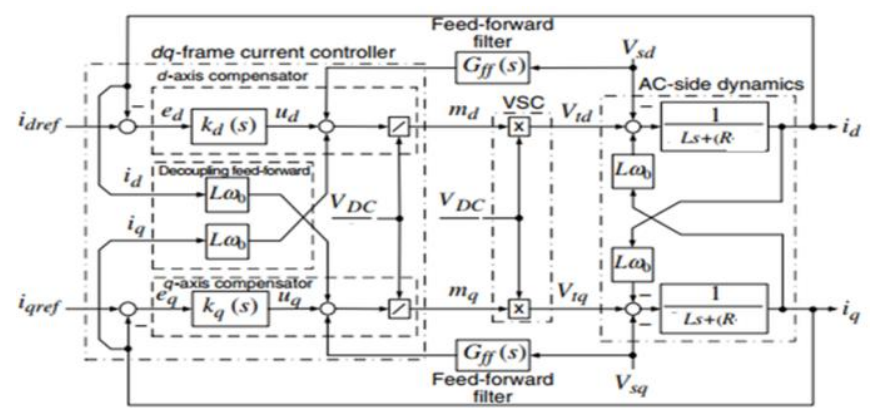

Figure 4: Current control algorithm for grid connected system

second approach to the control of the real and reactive power in the VSC system used in this research is referred to as the current-mode control. In this approach, the VSC line current is tightly regulated by a dedicated current-control scheme, through the VSC AC-side terminal voltage [6]. Then, the real and reactive power are controlled by the phase angle and the amplitude of the VSC line current with respect to the PCC voltage.[2]

The feedback and feed-forward signals are first transformed to the dq-frame and then processed by compensators to produce the control signals in dq-frame. Finally, the control signals are transformed to the abc-frame and fed to the VSC. To protect the VSC, the reference commands $\mathrm{id}_{\text {ref }}$ and $\mathrm{iq}_{\mathrm{ref}}$ as in figure 4 are limited by the corresponding saturation blocks. First order equation for control algorithm of figure 4 is given by equation 10 and 11 . 


$$
\begin{aligned}
& \frac{L d i_{d}}{d t}=L * w o * i_{q}-R * i_{d i}+V i_{d i}-V s d \\
& \frac{L d i_{q}}{d t}=-L * \text { wo } * i_{d}-R * i_{q}-V s q
\end{aligned}
$$

The modulating signal for the inverter PWM in $\mathrm{d}$ and $\mathrm{q}$ axis is given as below:

$$
\begin{aligned}
& m_{d}=\left(u_{d}-L * w o * i_{d}+V s_{d}\right) / V d c \\
& m_{q}=\left(u_{q}+L * \text { wo } i_{d}+V s_{q}\right) / V d c
\end{aligned}
$$

Then this signal is needed to transformed from dq to single phase axis. The capacitance in LCL filter circuit is removed from the control algorithm to ease the calculation, as it is used to provide the reactive power for the filter and switching process which doesn't much impact in the active power transfer.

$\mathrm{Vdc}_{\mathrm{ref}}$ is the reference bus voltage considered which is obtained from MPPT.As we know that with reference to Voltage, current of the PV cell changes, thus refence dc voltage track the MPP Voltage, causing the Vdc (solar PV voltage) to follow till the difference is zero. This algorithm tracks and provides the Reference current required for the comparison in the control algorithm. The feedforward parameter provides the stability and control the surges that may arise during switching. Feedforward constant is assumed to be one in this case for simplicity.

\section{F. Simulation of integrated Model in Grid connected mode}

IEEE 13 bus system is considered for the proposed microgrid. At node 680, the solar PV module system is connected with step down transformer to $400 \mathrm{~V}$ line to line voltage. This microgrid is connected to standard infinite bus system i.e. Grid whose voltage and frequency assumed to be constant. Standard PV considered for this system is $2.8 \mathrm{~kW}$ in capacity for this paper.

\section{RESULT AND DISCUSSION}

After the detail calculation for the filter circuit parameter, following parameter were obtained for the microinverter configuration

\section{A. LCL parameter}

After the running the code and through iterating calculation, suitable parameter for the LCL filter are obtained which are as follow:

Inverter side inductor $(\mathrm{Li}$ or $\mathrm{L} 1)=1.7 \mathrm{mH}$

Grid side inductor ( $\mathrm{Lg}$ or L2) $=1.7 \mathrm{mH}$

Tuning capacitor $(\mathrm{Cf})=16.9 \mathrm{uF}$

Damping resistance $(\mathrm{Rd})=0.438 \mathrm{ohm}$

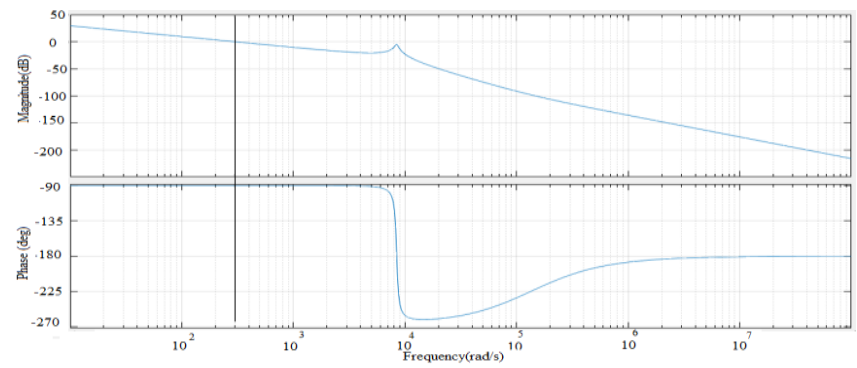

Figure 5: Bode plot of LCL parameter
Both Gain margin and phase margin of the bode plot are positive, system is stable from the parameter obtained.

After the detail calculation and analysis of the bode plot for tracking the grid current:

$\mathrm{Kp}=0.15$

$\mathrm{Ki}=16.6$

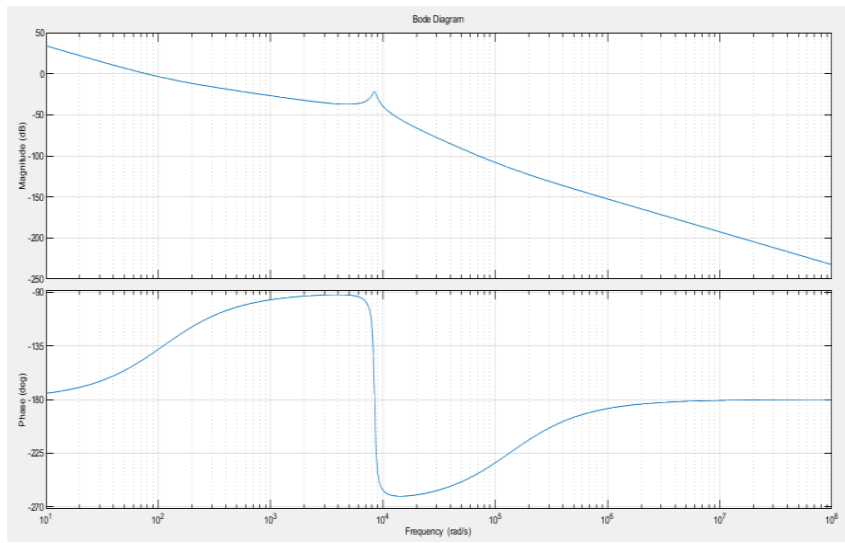

Figure 6:Bode plot of LCL parameter after K and Ki tuning

The system after the PI controller implementation is stable as both Gain margin and phase margin are positive. Again, System stability is checked when the series resistance is removed which is used in connection with the Capacitor of LCL filter.

There is exponential rise in gain at $w=10^{\wedge} 4$ radian ie frequency $=1504 \mathrm{hz}$ when $\mathrm{Rd}=0$. This effect the stability and performance of the system. From Figure 5 and 7, it can be seen that damping resistance is essential in series with capacitor. The considered system of figure 7 is unstable and has very high gain for high frequency signal. Thus, there is need of proper tuning of all the parameter if to eliminate the damping resistance.

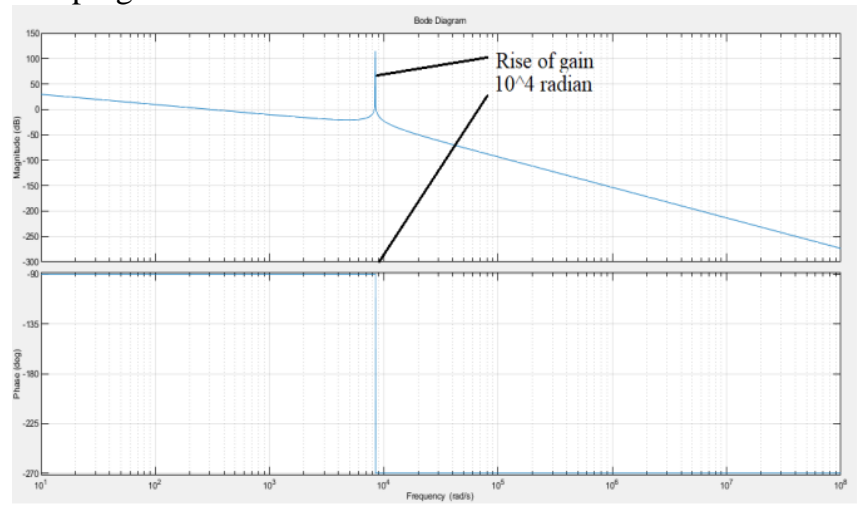

Figure 7:Bode plot when damping resistance, $\mathrm{Rd}=0$

\section{B. Performance of control algorithm of microinverter:}

The reference grid used is as $220 \mathrm{~V}(\mathrm{rms})$ grid maintained by the $14400 \mathrm{~V}$ grid with the transformer of $14400 / 220 \mathrm{~V}$ at PCC Detail Parameter and control algorithm after the obtaining above Filter parameter is simulated. After the simulation of the microinverter in the grid connected mode, following is the output voltage and current profile. Voltage of the grid and inverter are in sync due to implementation of PLL which show efficient tracking of the grid voltage and its phase. This shows the successful implementation of PLL tracking. The voltage is maintained at $14 \mathrm{~V}$ at the PCC before the transformer. There is no distortion in the voltage profile which is sinusoidal following the grid voltage with less harmonics. 
Irradiance is changed from $300 \mathrm{~W} / \mathrm{m}^{2}$ to $1000 \mathrm{~W} / \mathrm{m} 2$ and $800 \mathrm{~W} / \mathrm{m} 2$ at $0.6 \mathrm{sec}$ and $1.6 \mathrm{sec}$ respectively. From figure: 11 and figure:12, it can be observed that current seems to be sinusoidal at above irradiance. Along with that it can be observed that control algorithm has successful in tracking of the power due to changing irradiance with harmonic current less than $5 \%$.
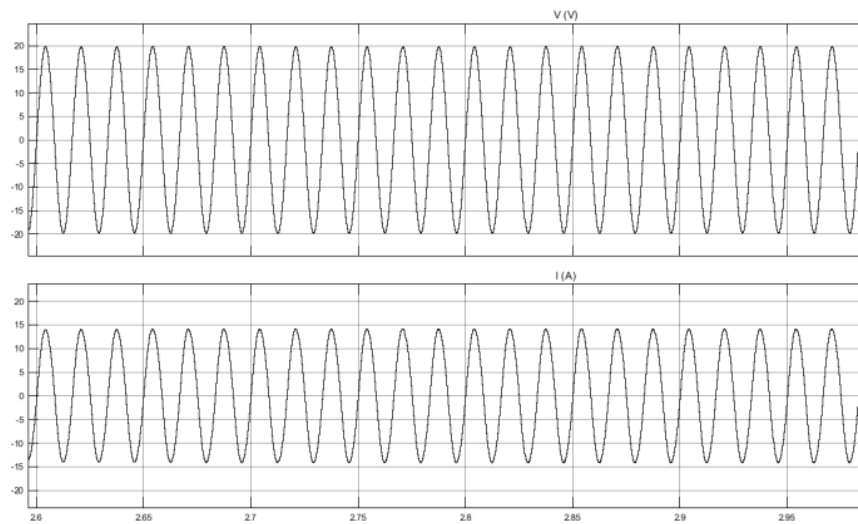

Figure 8: Sinusoidal voltage and current profile from $2.6 \mathrm{sec}$ to $3 \mathrm{sec}$ at $800 \mathrm{~W} / \mathrm{m} 2$

Coordinated current control technique with above designed LCL filter has provided efficient tracking of the power which is to be injected to the grid system.

From the figure 9, it can be observed that current injected to the grid by the microinverter PV system is tracking with the irradiance falling on the solar PV module. There is some lagging i.e. about $0.2 \mathrm{sec}$ to track the reference power which can be eliminated using advanced algorithm such as generic algorithm or neural network to obtained optimum parameter of LCL filter circuit recommended for future.

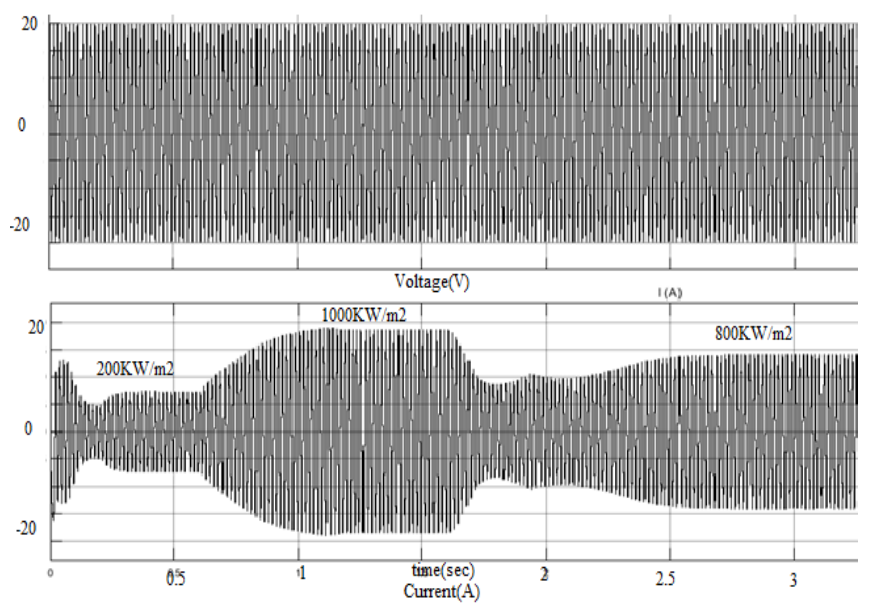

Figure 9:Voltage and current of inverter in grid connected mode with changing irradiance

\section{Analysis of Parallel Microinverter:}

About $2.8 \mathrm{~kW}$ capacity of PV system is considered in this simulation in MATLAB. So, 12 Parallel Microinverter system with capacity of $2.8 \mathrm{~kW}$ capacity, is connected to grid at $240 \mathrm{~V}$ (single Phase) through the common power transformer as proposed. $12 \mathrm{PV}$ module with parallel microinverter system with capacity of $2.8 \mathrm{~kW}$ capacity, is connected to grid at $240 \mathrm{~V}$ (single Phase) through the common line transformer as in figure 10 .

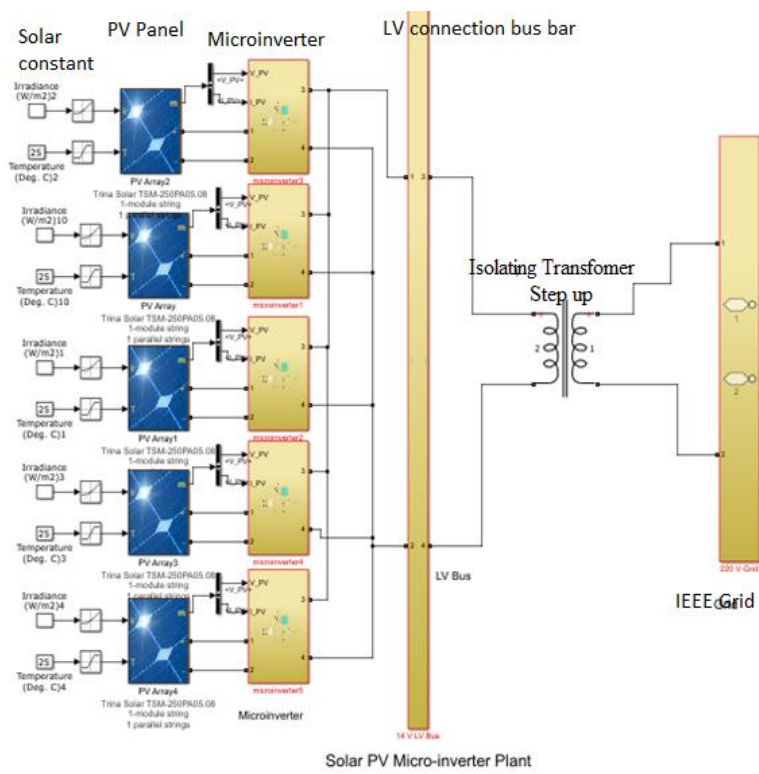

Figure 10: Parallel Microinverter system with line transformer

From the figure 11, it can be observed that output power decrease with respect to irradiance. Each microinverter module works independently, there is no mutual occurrence of loss of power due to shading effect.

For PV microinverter 1: when irradiance $(\mathrm{kW} / \mathrm{m} 2)$ is decreased to 1 to 0 at time $0.6 \mathrm{sec}$ of the simulation respectively, for PV array 2, irradiance $(\mathrm{Kw} / \mathrm{m} 2)$ is decreased to 1 to 0 at time $1.8 \mathrm{sec}$ and others all $10 \mathrm{PV}$ array are provided with irradiance $(\mathrm{Kw} / \mathrm{m} 2)$ of 0.9 to $0.6 \mathrm{~kW} / \mathrm{m} 2$ at time $1.6 \mathrm{sec}$ of the simulation. There is variation of irradiance on the PV module to simulate the effect of shading effect.

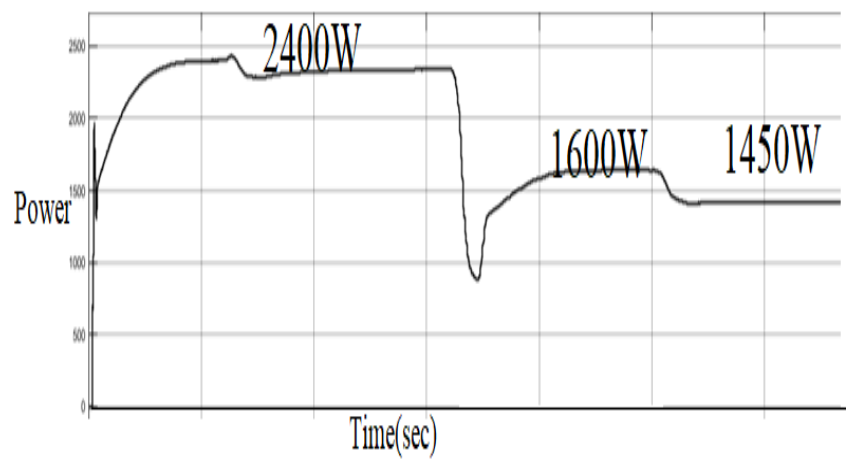

Figure 11: Active power injected to the grid by microinverter system

The figure 11 shows that there is no drastic drop of drop due to unequal illumination or irradiance on the PV module.

\section{Analysis of String PV Inverter System}

Similar Capacity of PV Grid tied system for String configuration is considered. String inverter system with 12PV array module in series with each module capacity equivalent of that of microinverter PV module of 250W. Each PV array is provided with bypass diode.

For PV array 1: when irradiance $(\mathrm{kW} / \mathrm{m} 2)$ is decreased to 1 , 0.6, 0.4 and 0 at time 00.61 .8 and $2.5 \mathrm{sec}$ respectively, for PV array 2: irradiance $(\mathrm{Kw} / \mathrm{m} 2)$ is decreased to $1,0.6,0.4$ and 0 at time 00.61 .8 and $2.5 \mathrm{sec}$ respectively and others all 10 series $\mathrm{PV}$ array are provided with irradiance $(\mathrm{Kw} / \mathrm{m} 2)$ of $1 \mathrm{~kW} / \mathrm{m} 2$. 


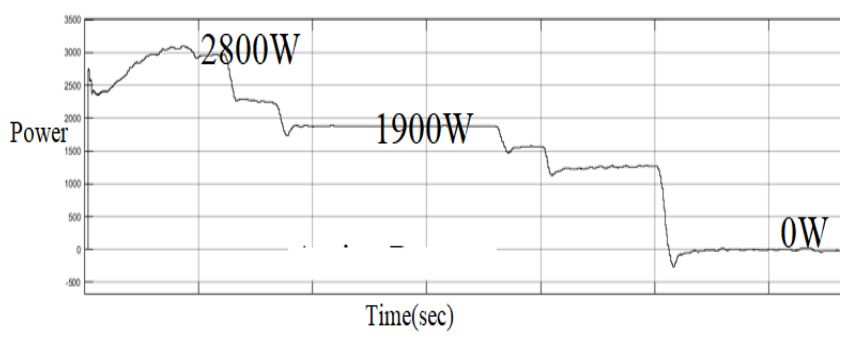

Figure 12: Active power injected to the grid by string PV inverter system

From above 12, it can be easily seen that power is drastically decreasing from $2.8 \mathrm{~kW}$ to $1.9 \mathrm{~kW}$ and $0 \mathrm{~kW}$ when irradiance on only two series PV array out of 12 PV array is partially to fully shaded.

Thus, Shading has serious effect on the performance despite the use of bypass diode. Bypass diode improve the power output of the system when there is limited number of shaded PV module. This is due to the fact that DC voltage input to the inverter should be greater than peak rms voltage of the grid. Thus, there is limit on the number of PV module getting shaded which cause failure of the string PV inverter-based grid tied system unlike Microinverter which are modular in operation.

\section{CONCLUSION}

Microinverter is very flexible and efficient energy source system in the Grid tied system. Design of LCL Filter circuit with current control algorithm helps to limit the harmonics within the standards. Current control mode is effective in implementation of grid tied inverter which provides smooth control over active power transfer to the grid. The total harmonic content has been limited to 5 percent. Shading effect is prone for string inverter PV system with respect to the microinverter system.

When more module is shaded then active power of the system is drastically decreased causing system to collapse in string configuration but there is no such serious concern for the microinverter system. Thus, Microinverter configuration designed above provides effective control over active power limiting the harmonics as well as galvanic isolation. So, well designed microinverter system provides modularity, efficient and reliable as compared with to string PV module. It can be considered economical alternative system to replace the conventional string PV inverter system.

\section{FUTURE RESEARCH WORK}

There is a lot of research area in design of LCL filter and control algorithm for single stage microinverter system. Size of filter circuit is significant which can be decreased further using advance control algorithm of design such as fuzzy logic or Generic algorithm to reduce harmonic content in the grid connected system. Current microinverter system is design for system solar farm in microgrid system, more discrete design and analysis can be done so as to reduce cost and complexity of the system for it to become economics for large solar PV system.

\section{REFERENCES}

[1] [1] Mehdi Seyedmahmoudian Ben Horan Rasedul Hasan, Saad Mekhilef. Grid-connected isolated pv microinverters: A review, 2017.

[2] [2] Li Fangxing and Adhikari Sarina. Coordinated v-f and $\mathrm{p}-\mathrm{q}$ control of solar photovoltaic generators with mppt and battery storage in microgrids, 2014.

[3] [3] Iravani Reza Yazdani Amirnaser. Voltgae controlled source converter in power system. Wiley, IEEE Press, 2010.

[4] [4] L Chaar B Crowhurst, E F Saadany and L A Lamont. Single-phase grid-tie inverter control using dq transform for active and reactive load power compensation. IEEE, 2010.

[5] [5] Solanki Mehul Yagnik Utsav. Comparison of l, lc and lcl filter for grid connected converter. International Conference on Trends in Electronics and Informatics, 2017.

[6] [6] Ravindra kumar Vinay sharma and Nishant Tripathi. Current mode controller design for single phase grid connected inver

Author

Sandesh Kunwar, Electrical Engineer, MSC in Renewable Engineering, Pulchowk Campus, IOE, TU

Co Author:

Dr Laxman Poudel, Professor, Mechanical Department, Pulchowk Campus,IOE, TU, Nepal 